\title{
AC 2011-783: IMPLEMENTATION OF AN INTEGRATED PROJECT-BASED APPROACH WITHIN AN ESTABLISHED AND EAC-OF -ABET ACCRED- ITED INTERDISCIPLINARY ELECTROMECHANICAL/BIOMEDICAL ENGINEERING PROGRAM
}

\section{Salah Badjou, Wentworth Institute of Technology}

Professor SALAH BADJOU, Ph.D. Wentworth Institute of Technology Electronics and Mechanical Engineering Department Boston, MA 02115 USA Email: badjous@ wit.edu Telephone: 6179894113.

Salah Badjou received a B.S. in physics and mathematics and a M.S.in physics from Syracuse University, Syracuse, NY, and a Ph.D. in solid-state physics from Northeastern University, Boston, MA. He has a combined multidisciplinary experience of more than 25 years university teaching, research, and industry. This includes two years, as a postdoctoral research fellow in chemical engineering at the National Center for Scientific Research in France (C.N.R.S.), and more than nine years teaching physics, electrical and mechanical engineering, mathematics, chemistry, physical science, astronomy, biology, and earth science at several colleges and universities throughout the USA. He worked as a high-voltage R\&D engineer at Thomson Consumer Electronics, Lancaster, PA from 1998 to 2000, and as a consultant in biomedical imaging (PET). He has been a full-time faculty in electronics and electromechanical engineering at Wentworth Institute of Technology since 2000, where he has been teaching in the areas of electronics and biomedical systems engineering, including five years of design courses. He has conducted research, with peer-reviewed publications, in biomedical engineering in the areas of biomechanics, bioelectricity, and biomedical imaging, since 1992. Other research interests include renewable energy, optical fiber communications, and project-based multidisciplinary and interdisciplinary education. 


\title{
IMPLEMENTATION OF AN INTEGRATED PROJECT-BASED APPROACH WITHIN AN ESTABLISHED EAC-OF-ABET ACCREDITED INTERDISCIPLINARY ELECTROMECHANICAL/BIOMEDICAL ENGINEERING PROGRAM
}

\begin{abstract}
A faculty-driven high-quality EAC-of-ABET accredited five-year interdisciplinary electromechanical engineering program was developed and implemented since 1992 at Wentworth Institute of Technology in Boston. The five-year program curriculum requires lab-based electrical and mechanical engineering courses, in addition to a one-semester junior design project and two semesters of a fifth-year design project, a freshmen design course, and a minimum of two semesters of coop training. Recently, the program has been further integrated with the addition of a biomedical systems engineering concentration. In the present article, the author reports on a novel approach to the teaching of traditional courses in the freshman and sophomore years, whereby student-centered design and research projects are introduced in preparation of the junior design project. The positive results and student feedback since the introduction of this method in spring 2006 and the possibility of generalizing this approach to other courses as well as the lessons learned are discussed. It was found that this approach significantly increases student motivation and performance in those courses and in junior design.
\end{abstract}

Keywords -Project-based, interdisciplinary, electromechanical, biomedical, education.

\section{Background}

A faculty-driven, high-quality EAC-of-ABET accredited five-year interdisciplinary electromechanical engineering program ${ }^{1}$ was established in 1992 at Wentworth Institute of Technology. Under EAC rules, the electromechanical engineering program had simultaneously met the accreditation criteria for electrical engineering and for mechanical engineering. The graduates of this program are true interdisciplinary engineers proficient in tackling interdisciplinary projects in all their electrical and mechanical complexity. In addition, the graduates have excellent laboratory and machine shop skills. Recently ${ }^{1,2}$ a biomedical systems engineering specialization was established in the form of a concentration within this well established electromechanical engineering program.

The addition of the concentration required only limited additional resources. The result is a high-quality program that is competitive with other biomedical engineering programs offered in Massachusetts. Effectively, this further integrates the electromechanical engineering program by incorporating the important biological dimension. The program has attracted a substantial number of students, and has expanded opportunities for our graduates. The Electromechanical Engineering Faculty Committee ${ }^{3}$ composed of eleven faculty members drawn from various disciplines, thoroughly researched, planned, and obtained administrative approval for the program, implemented, and is continuously assessing and fine-tuning this novel concentration. The endeavor was very much faculty driven. The faculty exercised care so that the addition of the new concentration did not alter or weaken the structure of the existing electromechanical engineering program but rather strengthened it, and provided greater opportunities for the graduates. The choice of elective courses from the life sciences, co-op employment in the biomedical field, and design projects with life-science applications made the implementation of 
this concentration possible. Graduates of such a program receive a Bachelor of Science degree in electromechanical engineering with a concentration in Biomedical Systems Engineering that is producing 3 engineers integrated in one.

The curriculum of the electromechanical engineering program with the biomedical Systems engineering concentration is described in Table 1 below. In addition to its strong interdisciplinary approach, the program is primarily project-based. This is done effectively as follows: in the second semester of their freshman year students enrolled in the program take a freshman introduction to engineering design course, ENGR 160, having 4 credits (2 lecture hours, 4 lab hours).In the spring semester of their junior year (3d year), students take a 3-credit junior design course (ELMC 461) having 1 lecture and 4 lab (consultation) hours per week. This course INTEGRATES all the knowledge acquired in their previous courses (1st and 2nd year and 1 st semester of 3 rd year) into the design of a full prototype of an original product. The following is the Wentworth catalogue description for ELMC 461:

Students work in teams to design and construct an interdisciplinary project. Teams, with clearly defined individual responsibilities, are required. During the course of the semester, each team undertakes the necessary activities to bring about a successful design project that is well understood, documented, and presented in both oral and written form. Emphasis is placed on research, innovation, project management, decision-making, prototyping, design for manufacturing, design for testability, environmental and ethical issues in design, depth and breadth of analysis, quality of hardware, documentation, and communications. Prerequisites: Junior Status; ELMC160 Electromechanical Design I; MECH302 Mechanics of Materials; ELEC244 Digital Systems; ELEC443 Analog Circuit Design.

Students are then required to take 2 semesters of senior capstone design course ( 8 credit hours), ELMC 831 and ELMC 881in their 5th year. Therefore, the design projects provide a focus and integrator of other more traditional courses. This approach has been very successful judging from winning numerous competitions both regional (ASME, IEEE) and national as well as the high demand in industry for graduates of this program. It has always been of interest to the Electromechanical Engineering Faculty Committee ${ }^{3}$ to continually find ways for improving the program. The present author, based on this objective and his experience (he joined this program in 2000), undertook a project since 2006, whereby he introduced on an experimental basis term projects in traditional courses he was teaching which typically, at Wentworth and in other colleges and universities, do not involve term projects. It started with Digital Systems, ELEC 244, taught for two years in Spring 2006 and 2007 and Network Theory II (ac circuits) another two years in Spring 2008 and 2009. All these courses are sophomore-level (see Table 1).

Another motivation for the author was that students traditionally had particular difficulties with Digital Systems (logic design and microcontrollers) and Network Theory II. The subject was either too abstract in Network Theory II (ac circuits), or too demanding; covering too much material some of it difficult (programming in Assembly Language) in Digital Systems. The author adopted a systems approach in his search for improvements. He tried to find effective ways to better motivate students, help them acquire a more enjoyable experience, while simultaneously enhancing the electromechanical engineering program. It was also hoped this would further help enhance student retention which is a major concern, as Wentworth Institute of Technology is a tuition-driven institution, especially in the critical sophomore year. Typically, a larger proportion of students drop out of the program at the end of their sophomore 


\begin{tabular}{|c|c|c|c|c|c|c|c|c|c|}
\hline \multicolumn{10}{|c|}{ First Year } \\
\hline \multicolumn{2}{|c|}{ Fall Semester } & \multirow{2}{*}{$\begin{array}{c}\text { Lec } \\
4\end{array}$} & \multirow{2}{*}{$\frac{\mathbf{L a b}}{0}$} & \multirow{2}{*}{$\frac{\mathrm{Cr}}{4}$} & \multicolumn{2}{|r|}{ Spring Semester } & \multirow{2}{*}{$\begin{array}{c}\text { Lec } \\
3\end{array}$} & \multirow{2}{*}{$\begin{array}{c}\text { Lab } \\
0\end{array}$} & \multirow{2}{*}{$\frac{\mathrm{Cr}}{3}$} \\
\hline ENGL100 & English I & & & & ENGL115 & English II & & & \\
\hline MATH265 & Engineering Math I & 3 & 2 & 4 & MATH280 & Calculus I & 4 & 0 & 4 \\
\hline CHEM100 & $\begin{array}{l}\text { Chemistry I } \\
\text { Introduction to }\end{array}$ & 3 & 2 & 4 & COMP120 & Computer Science I Using C & 3 & 2 & 4 \\
\hline \multirow[t]{2}{*}{ ENGR100 } & Engineering & 2 & 4 & $\underline{4}$ & PHYS310 & Engineering Physics I & 3 & 2 & 4 \\
\hline & & & & 16 & ENGR160 & Intro to Engineering Design & 2 & 4 & $\frac{4}{19}$ \\
\hline \multicolumn{10}{|c|}{ Second Year } \\
\hline ELECTIVE & $\begin{array}{l}\text { Social Science } \\
\text { Physiology for }\end{array}$ & 3 & 0 & 3 & ELECTIVE & Social Science & 3 & 0 & 3 \\
\hline ELECTIVE & $\overline{\text { Engineers I }}$ & 3 & 2 & 4 & MATH510 & Calculus III & 4 & 0 & 4 \\
\hline МАTH290 & Calculus II & 4 & 0 & 4 & ELEC281 & Network Theory II & 2 & 2 & 3 \\
\hline PHYS320 & Engineering Physics II & 3 & 2 & 4 & ELEC244 & Digital Systems & 3 & 2 & 4 \\
\hline ELEC231 & Network Theory I & 3 & 2 & $\underline{4}$ & MECH251 & Engineering Statics & 3 & 2 & 4 \\
\hline & & & & 19 & ENGL350 & Writing Competency & & & $\begin{array}{c}\underline{0} \\
18\end{array}$ \\
\hline \multicolumn{10}{|c|}{$\underline{\text { Summer Semester }}$ : Cooperative Work Semester - Optional } \\
\hline \multicolumn{10}{|c|}{ Third Year } \\
\hline ELECTIVE & $\begin{array}{l}\text { Physiology for } \\
\text { Engineers II } \\
\text { Applied Differential }\end{array}$ & 3 & 2 & 4 & MATH890 & $\begin{array}{l}\text { Linear Algebra \& Matrix } \\
\text { Theory }\end{array}$ & 4 & 0 & 4 \\
\hline MATH620 & Equations I & 4 & 0 & 4 & MECH565 & Engineering Fluids & 3 & 2 & 4 \\
\hline ELEC443 & Analog Circuit Design & 3 & 2 & 4 & ELEC471 & Embedded Computer Systems & 2 & 2 & 3 \\
\hline MECH302 & Mechanics of Materials & 3 & 2 & 4 & MECH496 & Material Science & 3 & 2 & 4 \\
\hline & Engineering & & & & & $\frac{\text { 3rd Year Engineering Design }}{\text { (must be in Biomedical }}$ & & & \\
\hline MECH505 & Thermodynamics & 3 & 2 & $\underline{4}$ & ELMC461 & Engineering) & 1 & 4 & $\underline{3}$ \\
\hline \multicolumn{10}{|c|}{$\begin{array}{c}20 \\
\text { Summer Semester: Cooperative Work Semester I - Required (must be in Biomedical Engineering) }\end{array}$} \\
\hline \multicolumn{10}{|c|}{ Fourth Year } \\
\hline MATH505 & $\begin{array}{l}\text { Probability \& Statistics } \\
\text { for Engineers } \\
\text { Engineering Signals \& }\end{array}$ & 4 & 0 & 4 & ELECTIVE & Humanities or Social Science & 4 & 0 & 4 \\
\hline ELEC584 & Systems & 3 & 2 & 4 & ELEC820 & Feedback and Controls & 3 & 2 & 4 \\
\hline ELEC586 & $\begin{array}{l}\text { Motors and Controls } \\
\text { Engineering Heat }\end{array}$ & 3 & 2 & 4 & MECH572 & $\begin{array}{l}\text { Engineering Dynamics } \\
\text { Advanced Mechanics of }\end{array}$ & 3 & 2 & 4 \\
\hline MECH595 & $\begin{array}{l}\text { Transfer } \\
\text { Technical }\end{array}$ & 3 & 2 & 4 & MECH600 & Materials & 3 & 2 & 4 \\
\hline COMM400 & Communications & 2 & 2 & $\underline{3}$ & MECH620 & Engineering Thermal Design & 1 & 4 & $\underline{3}$ \\
\hline \multicolumn{10}{|c|}{$\begin{array}{c}19 \\
\text { Summer Semester: Cooperative Work Semester II - Required (must be in Biomedical Engineering) }\end{array}$} \\
\hline \multicolumn{10}{|c|}{ Fifth Year } \\
\hline ELECTIVE & $\begin{array}{l}\text { Humanities or Social } \\
\text { Science } \\
\text { Biomedical Systems }\end{array}$ & 4 & 0 & 4 & ELECTIVE & Humanities or Social Science & 4 & 0 & 4 \\
\hline ELECTIVE & $\begin{array}{l}\text { Engineering } \\
\text { Electromechanical }\end{array}$ & 3 & 2 & 4 & MGMT510 & Engineering Economy & 3 & 0 & 3 \\
\hline ELMC815 & $\begin{array}{l}\text { Systems I } \\
\text { Senior Design I }\end{array}$ & 3 & 2 & 4 & ELMC870 & $\begin{array}{l}\text { Electromechanical Systems II } \\
\text { Senior Design II (Biomedical }\end{array}$ & 3 & 2 & 4 \\
\hline ELMC831 & (Biomedical Eng.) & 1 & 6 & $\underline{4}$ & ELMC881 & Eng) & 1 & 6 & $\underline{4}$ \\
\hline & & & & 16 & & & & & 15 \\
\hline
\end{tabular}


year than in other years. The author decided that since the focus and backbone of the program was design, this enhancement should also involve design.

Another potential area for improvement was in further integrating the courses in the program. It was agreed within the Electromechanical Engineering Faculty Committee ${ }^{3}$ that this integration is indeed not complete. How could one build effective bridges between the various courses, especially between the design and the other courses? How do we keep student interest and motivation high enough to go from the end of their freshman year all the way to the second semester of their junior year without being turned off or burned out by the level of abstractness of courses such as Statics, Network Theory, Digital Systems, Analog Circuit Design, Thermodynamics, Mechanics of Materials (see Table 1)? There seems to be a gap from the design and project point of view between the freshman and the junior year.

It was concluded progressively by the author that the best approach would be to require a term design project to be chosen by the students. The students would thereby themselves respond to their frequent but legitimate complaint: "Why are we doing all this abstract stuff?" Students would take the active role and "teach themselves" and creatively incorporate the material learned in a concurrent project of their "choice" instead of sitting passively in the lecture or lab doing what they are asked or "ordered" to do. The author planned to then draw conclusions on the basis of both performance and the end of semester questionnaire, ideally over several years of trying this approach. If feedback were positive enough then the experience would be continued with appropriate refinements as suggested by feedback.

One initial concern of the author was to not overload the students on top of their already demanding curriculum (see Table 1) where a typical semester load is 18 to 19 credits. At the same time, the author did not see how to eliminate completely lectures as the concepts and problem-solving had definitely to be discussed. On the other hand, based on his teaching experience, as far back as 1980, and as a student himself, the author was not too happy with the traditional lecture-based approach typical in college education. Looking back at his own experience both as a professional and a student, the author feels he certainly learned the most through real-life meaningful projects he liked. This being human nature should apply to all students. This is generally agreed by educators. ${ }^{4-7}$ In addition, he decided to give maximum freedom and initiative to students while "stepping in" only as a mentor to provide guidance and help when needed in their projects. He felt that this might hopefully help increase motivation as the students would thereby feel ownership of the fruit of their achievement. It is indeed "their" project and their "choice." This expectation was subsequently shown to be indeed the case as will be discussed below.

\section{How the project-based approach was implemented and the results obtained}

Students were required to form teams of up to 4 members and choose a project. A minimum of guidelines were given in a hand-out. Students were given a choice between a design and a term research paper on a special topic or biography of a major figure relating to the course material. In practice, most teams chose the rather more challenging design projects, and subsequent assessment showed these were the most effective both from the instructor's (the author) observations as well as student self-assessment. Weekly memos were required and students were strongly encouraged to meet outside class with the instructor (the author) to discuss their progress and get help when they need it.

This mentoring is similar to that done in junior design except that in junior design this was performed at consultation sessions (2 hours per week and per team) scheduled as "lab" 
sessions. In junior design, it was a requirement, while here it was optional.

A questionnaire was carefully designed to get accurate feedback at the end of the semester for assessment. The following question was asked relating to the term project:

What are your thoughts on the term project? How helpful was it to your learning? Do you recommend assigning it in future classes?

In the first year, in spring 2006, the author decided that $10 \%$ of the course grade would be assigned to the term project. Subsequently, encouraged by the success obtained, he increased the percentage to $15 \%$, in Spring 2007, 2008, and 2009, thereby reflecting the importance he gave to the project as a reliable partial measure of the learning achieved. The following grade distribution was chosen in teaching Network Theory II (ELEC 281) in Spring 2008 and 2009: Attendance, class participation: $10 \% 3$ tests: $30 \%$, 10\% each Lab projects: $20 \%$ Term project: !5\% Final Exam (cumulative): $25 \%$

Students were given the following guidelines: A formal report and 15 minutes presentation were due in the last week of classes. By comparison, Junior design presentations are 20 minutes long. Detailed guidelines for writing the final report, similar to those required in Junior design, were also provided. Two senior colleagues and members of the Electromechanical Engineering Faculty Committee ${ }^{3}$ were invited at the presentation in Spring 2006 and 2007. The performance of students was rather surprising and beyond the author's and his colleagues' expectations. The quality of all projects was not only generally very good but many of them went way beyond the level expected both technically as well as in the quality of the presentation. The following are examples of projects:

-Development of several alternative security systems

-Development of an internet-based microcontroller-interfaced control system.

In the author's view, the effectiveness of the oral presentations is probably an indication that the training students received in the spring semester freshman design ELMC 160 was effective and well done. From this feedback the author also concluded that there are always, as expected, students whose potential or level of preparation is above that expected in the particular course and therefore the traditional approach was rather confining and not the best it could be from the point of view of these students' education. This is especially true when the general level of preparation of the students is low. Even if only few students have these more advanced knowledge or experience or potential, they would be turned into mentors for their teammates. This is a motivating win-win situation for all. Student mentoring by their more advanced peers is indeed recognized by many educators ${ }^{4-7}$ as effective and beneficial to all involved.

Furthermore, the feedback from Spring 2006, showed the author that all students could and actually SHOULD be more trusted with more autonomy and initiative which is not at all the case with the traditional approach. This is confirmed by the consistent high level of performance of students in junior and 5 year design, where students enjoy a high level of autonomy and responsibility. Many educators have come to the same conclusion. ${ }^{6-7}$ Another exciting observation by the author was the high level of enthusiasm of all students which was beyond what was hoped for. The response to the end-of-semester questionnaires from students were all WITHOUT EXCEPTION positive and highly encouraging; all students felt the term project was a positive experience and consistently recommended that this approach be continued in the future. 
Based on this positive experience, the author decided to again assign a term project the following year in Spring 2007 when he taught again the same course Digital Systems, ELEC 244. The performance of students was again beyond the author's expectations confirming ALL of the conclusions from the previous year, and that this result was not a special coincidence unique to the particular class taught in 2006. Two senior electromechanical engineering faculty ${ }^{3}$ who were present at the final oral presentation were equally impressed. Student feedback in the end-of-semester questionnaire was again UNANIMOUSLY positive as in the previous year. In Spring 2007, and again in Spring 2008, the author also taught Junior Electromechanical Design. The students were those who took Digital Systems ELEC 244 the previous year, when the project-based approach was implemented by the author. Therefore, a possible effect on the students' ability could perhaps be assessed from the quality of the student projects.

The quality of the projects was very high. For example a team developed an internet-based control system, in spring 2006. In Spring 2008, the same team developed an impressive fully functional prototype of an electronic rubix game. Another team who developed a rudimentary robot in Digital Systems in Spring 2008 was able to develop a fully functional prototype of a BAPS board, a medical device to accurately monitor the rehabilitation of injured feet. Another team whose project was to develop software to drive a stepper motor with the M68HC12 microcontroller, incorporated the results in their junior design project in 2008. This project involved a complex system to automatically feed pets, which turned out to be one the most outstanding projects in the class according to the author as well as his senior peers who were at the final presentations.

The assessment in Spring 2007 from teaching ELEC 244 confirmed in all points that of Spring 2006. On this basis, the author decided to extend this method to other courses. In Spring 2008, he taught sophomore-level Network Theory II (ELEC 281) a particularly abstract traditional course involving analysis of ac circuits. He likewise assigned a term project. Here again student performance was excellent confirming the conclusions of the previous 2 years. Student feedback in the questionnaires was equally positive. The following are examples of projects.

-Design of two versions of a fully functional Tesla Coil by 2 separate teams

-Design of a fully functional Van-de-Graff generator

-Design of a fully functional wireless power transmission system building on the original ideas of Tesla.

In Spring 2009, the author had the same group of students in Junior design ELMC 461. Their performance was again very good and confirmed the conclusions of the previous year. This time the author wanted to quantify the possible correlation of student previous project performance in Network Theory on the basis not only of the quality of their designs but also by adding a question in the end-of-semester questionnaire and student course evaluation in junior design regarding how students felt their term project experience in the previous year prepared them for junior design. This is illustrated by comments such as the following, in response to the question: If applicable what are your thoughts about the term project? How helpful was it?

- Awesome, I had an opportunity to complete a project I had on my mind for a long time. I love having school projects overlap with a dream project and have it be relevant.

- The term project was very interesting and fun. Learned a lot, and I feel I am a little more prepared for the upcoming design class.

- The term project was a great idea and helped me gain some knowledge about circuits that I would not have otherwise gained through this particular course... maybe I will learn 
this next year, but right now I am ahead of the game. It was an essential preparation for what is to come

- The term project helped me understand certain concepts such as resonant frequency etc. It helped integrate theory and application. The term project is helpful in learning how certain things work in more detail

- At first I didn't like the idea, but after actually working on it my mind changed. It gave us an opportunity to apply what we learned in class and it improved my "gut feeling" about the effects produced by circuit components and what will and won't work in a circuit. Also our design involved components that we haven't studied yet, so it gave me an introduction to new things.

- It made us do research so we gained lots of knowledge.

- It is very helpful in understanding the basics (practical viewpoint)

- The term project was awesome. Learned a lot

The above comments are valuable in that they reveal the positive effects the term projects had on student education and perception. The least positive comment was from a student who wrote that he was not against having a project, but because of the volume of the work required in this and other courses, suggested that no final exam be given. The author feels that this particular student has a point and that ideally one would do away with the final exam, as in Junior Design, however he has concluded for now that the final exam is still necessary as a gauge of student understanding of concepts learned in the lecture. However, he feels that further improvements are possible.

In Spring 2009, the author taught again 2 groups (about 20 each) of students Network Theory ELEC 281. He assigned similarly a term project. Student performance was similarly positive and their feedback was as positive as the previous two years. The following are examples of projects:

-Design of a fully functional plasma-based music player.

-Design of a fully functional guitar amplifier system.

There were a few mild complaints about having too much work to do but no opposition to the idea of project. The following is the response of all students in Junior Design who completed the questionnaire in Spring 2009. They took Network Theory II a year earlier with the author. These were the same students who provided the above comments. In the author's opinion, their feedback is particularly valuable as these same students already gave their feedback right after completing their Network Theory II class in spring 2008, and then took Analog Circuit Design (ELEC 443) the following semester in Fall 2008, and then Junior Design in Spring 2009.

The following questions were asked in a questionnaire:

1- Please write your thoughts about last year project: How relevant to junior design was it in retrospect? Please provide detailed comments. Did it prepare you better and if so in what way did it prepare you better? Did it help you in future classes such as Analog Circuit Design and if so in what way?

2- Please include any other comments and recommendations you may have regarding if the projects should continue being assigned.

3- What are your thoughts and recommendations for possible improvements?

The following are student responses to questions 1 and 2:

1- It gave us past experience and the knowledge of how to present, write a proposal, and work together. Network Theory II helped immensely with signals, 
RMS values, and a huge part of the course. It also allowed us to better analyze circuits in Analog Circuit Design.

2- I believe it helped me get a better feel of working on design projects and this definitely did help in this Junior Design.

3- Network Theory II was extremely helpful to the course of Junior Design. It helped my teamwork abilities, communication, and research ability.

4- I enjoyed the semester project in Network Theory II. It was motivating, good team building and good practice for working with a team. This practice was perfectly good insight into Junior Design. Also, until this project, we had little practical experience, with analog design and parts. This semester project was a good hands-on learning experience in that regard as well as helping in both future classes and design. We were also exposed to analog circuits we have never seen until a future class.

5- I don't think last year project help in Junior design. I did not get much from the project, our project dealt more with research than anything....I think it should keep being assigned. It was really interesting to see other people's projects and I learned a great deal that way we are unfamiliar with. Last year project helped greatly with Analog Design because we accomplished research and design using components which were part of the curriculum.

6- The research done for last year project was helpful as an introduction to the research done in Junior Design. It allowed us to see how to come up with a concept then proving it will work, is the correct way to go in design.

7- The class was extremely helpful in both Junior Design and Analog Design. Building the guitar pedal was amazing help in circuit analysis for our junior design....Keep assigning projects, each project that I get helps me to grow closer to solidifying my knowledge in the engineering field.

8- I believe that any chance we get to have a design course, all of us as individuals benefit from researching, designing and building each project. Creating or building a project allows us to see what we are capable of. This will always be useful because it is essentially as if we were in the working world....I think these projects should continue since they help have a hands-on experience with classroom knowledge.

9- Unfortunately in application our project was not relevant, even though the subject matter was very similar. It was helpful however with providing a precedent for the kind of collaboration and work ethic required of the project moving. Unfortunately this ethic was lost between semesters.....Actually; I believe there should be two projects one due at midterm, one at the final as usual....

10-I think it did help with both Junior Design and future classes because it was one of the first projects we got to work on. It gave us experience in research and design and opened our knowledge about the electrical and mechanical world that is not discussed in classes...I think a progress report would help students to be aware of how much progress they made and give them some experience with presenting before a group...The projects should still be assigned in my opinion because it lets the students get their feet wet with research and design before they enter Junior Design. It also keeps their minds more open in future classes.

11- I believe that the project that I did last year in Network Theory II prepared me well for future classes. My project was to design and build an electrical distortion pedal for an electric guitar. The circuitry which my group and I eventually designed had components in it which we hadn't learned about yet. Due to this, we were forced to 
do research and study these components characteristics before ever being taught them. This gave us a head start on those topics when we reached them in class...I believe that these projects should still keep being assigned but maybe with just a little more direction....

12- It was very helpful. It gave us an idea of what you would expect for Junior Design a year later. Our project didn't really have anything to do with analog, but we researched material which was taught at the end of Network Theory...The projects should be continued, it's a great way to give samples of what it is like in the work force, and gives good hands-on experience.

13- I think a sophomore design project is a great idea. Building a Tesla coil allowed me to gain much more knowledge in the electrical area. Resonance, when described in class, was vague, and after making use of it in the design of the Tesla coil it became easier and much more interesting. As far as helping in future classes, as of now, I don't believe it helped but it along with my Junior Design project have allowed me to learn more than I have in any other class.....I believe 100\% that projects should continue to be assigned. More learning can be achieved in 1 semester on a project than could be in 4 years of lectures.

14- I believe that last year design project helped a great deal for junior design. It gave us a better sense of knowing what to expect with working with a group and from the professor. It helped a great deal in Junior Design....I believe the projects should be still assigned because it is good to do something that you already have experience on.

15-Design is a large aspect. It really makes the student think outside the box and on a larger "system" scale that isn't seen in class. It is very important to be able to apply what is learned to a practical application which gives the student more knowledge of the subject matter. It did help in Analog Circuit Design as well as Junior Design, because it helped to learn how to think practically and how to learn new concepts in order to apply it to the system as a whole...I believe the projects are very good, as long as it's not the basis of the course. It is a lot of extra work on top of 5 classes, so if it isn't too much extra strain it would be excellent.

16 - Comparing Junior Design to the Network Theory II design, I hadn't taken the Network Theory design too seriously. We didn't really get too much done until the very end where we threw things together quickly. However, it did provide insight into what was required for a design project. It helped put the principles of Net Theory in perspective...[Continuing assigning a term project] is a good idea in that it provides something real and tangible to reinforce the theory of the class.

17- I think it did help in future classes because it was practice for us. It helped us to work in groups, but also to work as individuals on the same project. It also helped us to understand how hard a project might get so we knew to better manage our time....I think they should still be assigned.

18- A main advantage the project gave was that I became better prepared for specifically how you as the professor were going to approach Junior Design. Additionally, this project taught me how to learn on my own about concepts which had not yet been introduced through classes. I was able to take that experience and use it when I needed to learn new things associated with my Junior Design project... The earlier students gain confidence in researching and educating themselves on new, but unrelated topics, the better. It is a great advantage to be able to learn on one's own, and I would suggest that research be a critical component to sophomore projects. 19-I feel that the projects that were done in ELEC 281 did help prepare us a bit for 
Junior Design. They helped because we had to build something relevant to the course, test it, and present our results and research.... think they should still be assigned.

20- Last year design project prepared us for how much was needed to be done in a small amount of time. The biggest benefit was seeing how long it took to complete the project...The project should be kept being assigned to expose students to what they will be expected to do later.

21-The project was relevant to Junior Design because it gave us a taste of how to do a design project. This project however was not involved enough to truly give us an understanding of what Junior Design would be. This project did not have a significant bearing on my other classes such as Analog Circuits... The project is a good concept but if it is to be assigned in the future, there should be more instruction that is put into the project.

22- The project was very relevant to Junior Design. It made us more confident in researching and implementing devices

\section{Discussion}

A term Project was assigned in a total of 4 classes: Digital Systems (ELEC 244) in Spring 2006 and 2007, and in Network Theory II (ELEC 281) in Spring 2008 and Spring 2009. The following was observed:

1- Students' projects quality was beyond expectation: Many were able to successfully tackle material from more advanced classes. Such material did not discourage the students from successfully completing their projects. Students explicitly stated as illustrated in the above comments they felt this was a positive experience. In the author's view this indicates that students could be trusted tackling more advanced material on their own as long as the motivation is there.

2- There was much enthusiasm, self confidence and pride among all students.

3- There was appreciation by many students for the research skills acquired in their term project. This confirms the conclusion of the National Academy of Engineering in their report $^{5}$ of 2005, The Engineer of 2020.

4- The term-design project is a highly effective generator of motivation as consistently observed by the instructor (the author) as well as confirmed by the above student response to end-of-semester questionnaires and course evaluation. The most negative response was from a single student who was not opposed to the idea of project but to the volume of work and suggested not having the final exam while keeping the term project. Generally a few students in all 4 classes taught with a term project raised mild concern of overloading. This suggests areas of improvements as to possible lightening the work in other aspects of the course. A more effective approach would be a more comprehensive curriculum design, which however will be more difficult to implement by the instructor.

5- The author also concludes that the more gifted and better prepared students are also given a valuable opportunity for a fuller use and development of their potential, getting more out of their education and for being mentors to their teammates. In the traditional lecture-based framework students are deprived of such opportunities.

6- In the author's opinion, students' universal high degree of enthusiasm and motivation shows that it is likely that this experience has had a positive effect on retention, though this needs to be confirmed by a more reliable measure and additional feedback in the future. A 
possible project for the future is an actual more quantitative monitoring of retention and its correlation with this design experience. If this conclusion is true, as it is likely to be, this would be an additional means of improving retention, in addition to the introduction by a team of electromechanical engineering colleagues ${ }^{3}$ of the Freshman Mentoring program they introduced a few years ago, ${ }^{4}$ whereby freshmen in Introduction to Engineering course (see Table 1) are teamed with 5th year design teams, helping them while gaining valuable hands-on project experience. The authors found this led to improvements in retention. Carefully designed questionnaires for future seniors could provide valuable feedback regarding this question. In fact, the idea of introducing term design projects in the sophomore year would then be a nice complement to this freshman mentoring initiative $e^{4}$ as it addresses the critical transition between the freshman and the Junior years.

7- Valuable feedback and insight was provided by students as is partially reflected in the above student comments. All the feedback, most of it constructive, is being incorporated by the author with his new classes. This includes making the term projects look more like Junior Design such as requiring midterm progress reports and presentations, while making sure no overloading of students occurs. Another one is requiring design projects of all students as recommended by several students. Another one is to encourage students to brainstorm on a possible junior design project and focus in the given course on building the module of the anticipated junior design project that is related to the subject matter being taught. The students will still have the option to choose a different topic in Junior Design.

8- All these changes were implemented by the author in his teaching of Analog Circuit Design (ELEC 443) in Fall 2009. The same students then took their Junior Electromechanical Design course the following semester, in Spring 2010. Student feedback in Analog Circuit Design indicated that many students were enthusiastic and positive about their project experience. However, the author was surprised to observe that more students than in previous classes complained of lack of time. This particular course is more demanding than the previous courses of Network Theory and Digital Systems where projects were introduced. In addition, it is offered at a different time, in the fall, when students enroll in more demanding engineering courses. In addition, the instructor (the author) observed that this particular class was generally not as well prepared as his previous classes. Because of this, and especially because in the following semester the same students are required to take Junior Electromechanical Design, the author concluded that with the current curriculum design, it will probably be more appropriate to implement scaled down design projects a few weeks in duration in the lab instead of a term project. The author in fact implemented this approach in his teaching of the fifth-year level Electromechanical Systems II in Spring 2010. Because students were concurrently taking their Capstone Senior Design project, the author assigned two design mini-projects, one in sound and another in image processing. Each project lasted about 3 weeks and the results demonstrated in the lab. Student feedback indicated the projects were well received. Additional ways to implement project activity are currently being researched by the author.

\section{Conclusions}

Based on the above experience, the author believes that the introduction of term design projects in courses which are traditionally lecture and lab based and have no projects in the sophomore years are highly beneficial to student education, help student future performance in design, significantly increase their motivation, and improve retention. They help establish the 
desirable sought-for bridges between traditional courses and the core design courses of the electromechanical engineering program at Wentworth Institute of Technology, thereby more

effectively integrating student education. ${ }^{1,2}$ The author further believes that such an approach could be generalized to other non-design courses in the curriculum such as courses taken in the $3 \mathrm{~d}$ and 4th year (see Table 1) that would establish bridges to the capstone 5th year design. Also based on recommendations from students in Spring 2009 junior design who took Network Theory II with the term project in Spring 2008, as well as the better performance of those students who chose a design project, the author decided that future projects would all be required to be design projects instead of also allowing research papers on special topics.

The author plans to continue refining this approach as well as continue assessment while refining the assessment method as well. For example in Fall 2009, the author taught Analog Circuit Design (ELEC 443) to the same two groups of students (about 20 each) who took Junior design the following semester (Spring 2010). The author again assigned term projects and made the requirements closer to those of junior design. Student feedback indicated that the term project was a positive experience for many students but it was overwhelming for a significant number of students and may be better replaced by one or two smaller-scale lab projects. This particular class was different from previous classes in that students were generally less prepared and the course material more demanding. In Spring 2010, The students who performed well in their Analog Circuit Design projects clearly performed better in Junior design and indicated so in their end-of-semester assessment. The author also introduced projects in a fifth year-level Electromechanical Systems course in Spring 2010. Because the students were concurrently taking Capstone Senior Electromechanical Design, the author assigned two mini-projects a few weeks long, one in sound and another in image processing, instead of a term project. During these last few years the author has been further researching effective philosophies and practices of education $^{5-7}$ which confirmed his conclusions that having students choose and work on a significant real-life projects involving the design of a tangible product that satisfies a need with students having maximum initiative while being discretely mentored by the instructor merely as a "guide", as needed, motivates significantly the students, make them more creative and self-confident, and help them achieve their full and true potential, and perform better in subsequent design projects.

\section{Acknowledgements:}

The author wishes to thank all his students who took part in this exciting experiment, Particularly those who took Digital Systems in Spring 2006 and 2007, Network Theory II in Spring 2008 and 2009, Electromechanical Systems II in Spring 2010, and especially the 2011 graduating class who took Network Theory II in Spring 2008 and Junior Design in Spring 2009. The feedback of these students was very valuable. The author also thanks the Electromechanical Engineering Faculty Committee, especially those members who gave him valuable feedback and encouragement after attending various student presentations including, Dr. Loutfallah Georges Chedid, Dean Fred Driscoll, Professors Robert Villanucci, Harry Avakian, and Dr Ray Tavares.

\section{References}

[1]-Salah Badjou, Loutfallah Georges Chedid Implementation of a Novel Biomedical Systems Engineering Concentration Within An Established And EAC-of-ABET Accredited Electromechanical Engineering Program 
Proceedings of the 2009 ASEE Annual Conference, Illinois/Indiana Section Conference, June 14-17, 2009.

[2]-Loutfallah Georges Chedid, Salah Badjou, Introduction of a Novel Biomedical Engineering Concentration into an Interdisciplinary Engineering Program and Lessons Learned, 2007 Illinois/Indiana ASEE Section Conference, March 30-31, 2007.

[3]-Internal documents about the Electromechanical Engineering Faculty Committee structure: In summary, this eleven-member interdisciplinary and interdepartmental committee is composed of four faculty members with electrical engineering, one with physics/biophysics, four with mechanical engineering, one with interdisciplinary electrical and manufacturing engineering, one with mathematics, and one with industrial psychology background and expertise. This standing committee has worked together as a cohesive team for more than ten years, and has been responsible for designing, implementing, and overseeing a unique-in-the-nation five-year electromechanical engineering program. This program is the only one of its kind in the US that is currently accredited by EAC of ABET.

[4]-Loutfallah Georges Chedid, Frederick Driscoll, Raymond Tavares, and Harry Avakian, Mentoring of First-Year Engineering Students: A Pedagogic Tool for Success, Internal Communication.

[5]-Educating the engineer of 2020: adapting engineering education to the new century, National Academy of Engineering, National Academic Press, 2005

[6]-Ester Wojcicki, Setting up a Successful Journalistic Learning Community: Educational Theory Supporting Project Based Learning (PBL) and Learning Communities, http://gallery.carnegiefoundation.org/collections/castl_k12/ewojcicki2/research/PBL_research.htm

[7]-John Taylor Gatto, The Underground History of American Education: A School Teacher's Intimate Investigation Into the Problems of Modern Education, The Odysseus Group, NY, USA, 2000. 